\title{
Entrepreneurship and organizational performance: Empirical insight into the role of entrepre- neurial training, culture and government funding across higher education institutions in Paki- stan
}

\author{
Nadeem Khalid $^{a^{*}}$, Umair Ahmed ${ }^{b}$, Bakytgul Tundikbayeva ${ }^{c}$ and Marwa Ahmed
}

${ }^{a}$ KIMEP University, Kazakhstan

${ }^{b}$ Arab Open University, Bahrain

${ }^{c}$ KIMEP University, Kazakhstan

${ }^{d}$ University Utara Malaysia, Malaysia

CH R O N I C L E

\author{
A B S T R A C T
}

Article history:

Received: November 10, 2018

Received in revised format: November 20, 2018

Accepted: January 28, 2019

Available online:

January 28, 2019

\section{Keywords:}

Entrepreneurial training

Entrepreneurial culture

Organizational performance

Government funding

Moderation

\begin{abstract}
This paper examines the relationship between entrepreneurial training, entrepreneurial culture and organizational performance. Accordingly, the study also investigates the moderating effect of government funding on the relationship between entrepreneurial culture, entrepreneurial training and business performance among the public universities in Pakistan. The respondents include 415 heads of department out of 1100 identified in the study. Structural equation modeling using PLS 2.0 M3 reports significant relationship between entrepreneurial training and organizational performance. Likewise, entrepreneurial culture is also reported to be significantly important for boosting organizational performance. Importantly, the study reports significant moderation of government funding on the relationship between entrepreneurial culture and organizational performance. However, no moderation is reported on the entrepreneurial training and organizational performance relationship. The findings of this study have enhanced the understanding regarding government funding in the prospect of improving the performance of the HEIs in Pakistan. The study recommends that the state government and higher education institutions in Pakistan allow room for entrepreneurial activities, and development of entrepreneurial principles and opportunities, and further encourage entrepreneurial practices through the development of public entrepreneurial orientation and entrepreneurial training on innovation to generate/create positive effects on the organizational performance of HEIs.
\end{abstract}

C 2019 by the authors; licensee Growing Science, Canada

\section{Introduction}

Entrepreneurial progression plays a vital role for the strategic growth and sustenance of any business and/or corporate entity (Umrani et al., 2016). The Malaysian economy has been actively working to infuse entrepreneurial environment in the society to enhance national and business level outcomes (Ariff \& Abubakar, 2002; Robuan et al., 2017). 
In particular, the government is striving its best to increase entrepreneurial activities in order to help the economy thrive in the current turbulent financial conditions (Nor, 2015). Since the public-sector institutions rely heavily on the financial and non-financial support and facilitation from the government (Else, 2016), the public authorities need to understand the strong impact of its support towards the appropriate working, operational effectiveness and achievement of business performance expectations. Sadly, the Malaysian economy has been facing similar blustery economic situation due to which, the government has made considerable budget and funding cuts in all sectors including education (MOF, 2016). Notably, to tackle such critical and turbulent economic conditions, nations across the globe have started encouraging general public to engage in entrepreneurial activities to help withstand tough financial situations. In parallel, government authorities have also been indicated to understand their role especially when it comes to supporting financially (Winter et al., 2006). Likewise, when it comes to motivating people in the public sector to enhance performance, the element of funding support alongside entrepreneurial prospects has become even more important (Mok, 2005). Henceforth, the present study attempts to examine as to how government funding can add value and enrich the conventional entrepreneurial prospects such as entrepreneurial training and entrepreneurial culture to boost organizational performance. The study has attempted to address major theoretical gap in the literatures pertaining to the buffering role of government funding prospects, especially for public sector institutions to flourish entrepreneurial practices for higher organizational performance.

\section{Literature Review}

\subsection{Organizational performance}

Researchers have provided many definitions of organizational performance though most of them have defined it in the sense of a private or profit-making organization. Definition by Antony and Bhattacharyya (2010) is worth considering who have defined organizational performance as the measure that can evaluate and appraise to convey and formulate value for external and internal shareholders of the organization. Accordingly, Adams et al. (2014) studied public sector performance and defined it as value creation for the external and internal stakeholders. Entrepreneurship also has direct positive relationship with organizational performance (Sambrook \& Roberts, 2005). Researchers believe that entrepreneurship at organizational level can improve performance. Previous researches have adumbrated that organizations benefit from their capacity of risk-taking and adoption of new ideas and trends (McKinley et al., 2014). Therein, studies have also reported the significance of entrepreneurial prospects provided by organizations for boosting organizational performance in various occupational settings (Delaney \& Huselid, 1996; Umrani et al., 2016).

\subsection{Entrepreneurial Training}

Training is an important function that can help develop competitive skills in employees for responsive performance and employee outcomes (Ahmed et al., 2016; Kuvaas, 2008). Accordingly, entrepreneurial training offers similar prospects. Researchers have reported that entrepreneurial training in organizations can turn out to as an effective growth strategy to achieve competitive advantage (Ahmed et al., 2016; Lumpkin \& Dess, 1996; Pinchot, 1985). Moreover, entrepreneurial training can considerably foster organizational wellbeing as when workers are trained in a certain domain, they become capable of handling different challenges in a responsive manner (Codrina, 2008). Such individuals give out their best which ultimately leads towards the high rate of performance of organisation.

Kithae et al. (2013) asserted that, entrepreneurship training is important as it facilitates the core development and growth of major business sectors. It has been recognized as an important tool for changing the attitude and transfer of skills to people with entrepreneurial traits. The review has also enumerated findings of various researches related to training programs. Among key guidelines are the content, procedures of selecting appropriate trainers, trainees and the training facilities and methods. However, 
despite the fact that entrepreneurship training has been reported to have a substantial impact on performance prospects yet still; little has been devoted concerning to its impact on organizational outcomes for better generalizable understanding (McKenzie, \& Woodruff, 2013).

Researchers have also indicated the significance of entrepreneurial training for public authorities and government institutions to help them achieve corporate goals with innovative ideas to improve their performance and efficiency. Unquestionably, education and learning can play a vital role for all positive outcomes and prospects (Kearney et al., 2009). Rosli and Mahmood (2013) stated that the effect of entrepreneurial training on the relationship towards organizational performance is very limited. In parallel, different training prospects have also been reported with considerable influence on organizational performance (Úbeda-García et al., 2013). Likewise, public sector institutions and entities are also realizing the importance of entrepreneurial training to boost performance and operational excellence (Morris \& Jones, 1999) but there is a limited evidence concerning to this. Henceforth, keeping the contemporary evidences pertaining to the viability of entrepreneurial training beforehand, it was perceived that entrepreneurial training would also help enhance performance aspects across the public-sector universities in Malaysia.

$\mathrm{H}_{1}$ : There is a positive relationship between entrepreneurial training and organizational performance.

\subsection{Entrepreneurial Culture}

Martins and Terblanche (2003) documented culture as an important internal organizational component, which backs up the entrepreneurial activities in a work setting (Zare \& Shakeri, 2011). Cultural factors encourage new ideas and innovation in the organization, which enhances their efficiency (Miron et al., 2004). Organizational culture has appeared to be a vital source of sustained competitive advantage for the organizations due to its unique characteristics such as value creation, unique human and mechanical assets (Noguera et al., 2013; Hayton, 2005). Researchers have described that organizational culture which encourages new ideas, openness and information sharing are more proactive performers. Accordingly, studies have also revealed that sustainable organizational culture has positive impact on employee performance which can further lead towards betterment in organizational performance (Lok et al., 2005). Importantly, some empirical evidence also suggests no relationship between culture and performance (Kim et al., 1995). Wherein, some references can also be tracked outlining a significantly positive relationship between cultural factors and organizational performance (Aluku, 2003). Following the discussion on various relationships in the previous studies, this current study formulated to test the following:

$\mathrm{H}_{2}$ : There is a positive relationship between Entrepreneurial culture and Organizational performance.

\subsection{Statistics on HEIs and Government Funding in Pakistan}

The Higher Education Commission of Pakistan (HEC), formerly known as the University Grant Commission (UGC), is responsible for the regulation of higher education in Pakistan. Universities in Pakistan were recognized by the UGC until 2002, according to The University Grants Commission Act, 1974. This Act was rescinded in 2002 by the Higher Education Commission Ordinance, 2002 and since then, Higher Education Commission of Pakistan (HEC) is a primary regulator and responsible for higher education regarding quality assurance, policy making, degree attestation and recognition, uplift of existing institutions and development of new institutions in Pakistan. HEC has also played and continues to play her role in the development of higher educational system in Pakistan. The primary objective of its establishment was the up gradation of universities in Pakistan for creating a center of research, development and education. The HEC has played an important role in building a knowledge based economy in Pakistan by sponsoring hundreds of doctoral scholars for education abroad every year. The quality of Higher Education is a significant and vital factor for the success and development 
of any country. The initiators of change and development of the culture and technology are considered to be the role of Higher Education Institutes (HEIs). In the context of globalization, according to the report of Quality and Research Based Ranking of Pakistani HEIs (2013), HEIs are the source of social change through the dissemination of the knowledge. As the Higher Education Institutes come under the purview of the Higher Education Commission, the quality enhancement and assurance of the education constitute the sole purpose of the Higher Education Commission. According to Ahmed (2013), the quality assurance programs by the Higher Education Commission focus mainly on three broader areas which are; to sensitize the academia to the standards and quality, to develop these standards and to build the capacity of Higher Education Institutes for the implementation of these standards for quality improvement and further evaluate the implementation in order to reflect the culture. During the last decade, the Higher Education Commission of Pakistan has done tremendous work in the field of education. Quality enhancement of the Higher Education Institutes has always been the main focus of the Higher Education Commission. Moreover, Ahmed (2013) stated that increasing the output of quality research from different Pakistani universities, development of qualified human resources, maximizing equitable access and improving academia-industry linkages have been among the focus of the Higher Education Commission. It has also worked to strengthen physical and technological infrastructure of the universities.

The Higher Education Institutes of Pakistan includes various public, private and Degree Awarding Institutes (DAIs). According to the latest report (2015), the figure of public and private sector HEIs varies where public sector institutes are more in number than the latter. The total number of universities according to a survey in 2014 was 163 . The distribution of universities as public and private sectors is given in Table 1.

Table 1

Number of Public and Private Sector Universities/DAI by Region

\begin{tabular}{llll}
\hline Region & Public & Private & Total \\
\hline Punjab & 20 & 22 & 44 \\
Sindh & 17 & 30 & 47 \\
Khyber Pakhtunkhwa (KPK) & 19 & 10 & 29 \\
Baluchistan & 6 & 2 & 8 \\
Federal & 24 & 6 & 30 \\
Azad Jammu \&Kashmir (AJK) & 4 & 2 & 6 \\
Gilgit-Baltistan (GB) & 1 & 0 & 1 \\
\hline Total & 91 & 72 & 163 \\
\hline Source: Higher Education Commission Pakistan, 2016 & & &
\end{tabular}

It can be seen from the table that out of 163 universities, 91 are public universities whereas 72 are private/DAIs institutions. Punjab province has 44 Universities/DAIs institutions out of which 22 are public and 22 are private. Sindh province has a total number of 47 Universities/DAIs institutions with 17 public and 30 private. Khyber Pakhtoon Khwa has 29 Universities/DAIs institutions out of which 19 are public and 10 are private. Whereas Baluchistan has 8 Universities/DAIs institutions, 6 public and 2 private, the Federal Territory has 30 Universities/DAIs institutions, 24 are public and 6 are private. Azad Jammu and Kashmir (AJK) has a total of 6 Universities/DAIs institutions out of which 4 are public and 2 are private, Gilgit-Baltistan (GB) has only 1 university which is public university. Different regions of Pakistan in which these institutions lie are also mentioned in the above table. This table shows that Punjab has the maximum number of private institutes while the federal sector has more public universities.

\subsection{Moderation of Government Funding}

It is the duty of the federal government to fund the commission on its requirement. In Pakistan, grants can be approved under President Ordinance, which was passed in the year 2002. In Malaysia, public sector universities heavily rely on government funding. 
The political environment of public sector activity has been of a critical significance for public sector management. Attention and support of government towards institutions and departments can accelerate outputs and performance prospects (Chung et al., 2014). Scholarly studies have demonstrated the role of government funding in public sector universities. Ahmad et al. (2013) studied the funding reforms in Malaysian Public-sector universities and illustrated that funding system is one of the major influential factor for institutional performance. However, they suggested that when there is a lack of government funding then universities should ideally focus on their revenue resources. In parallel, the universities should also concentrate on improving their performance to get funding from federal government. However, there are not enough researches regarding government funding and its impact on organizational performance. Accordingly, government funding is very crucial especially for entrepreneurial prospects. For example, a study revealed that funding policies of Australian government helped many entrepreneurial initiatives and public-sector universities in elevating (Cumming, 2007). Similarly, Chinese government is also playing its part in motivating entrepreneurial activities in their country and providing hefty funding opportunities. Therein, the country has established an open economy over the last few decades whereby, funds can be obtained by innovative individuals. Moreover, government's funding polices are very flexible for entrepreneurs which includes tax incentives, macroeconomic policies, tax and land policies (Zhao \& Pira, 2013). Similarly, adequate government funding policy can boost the performance of public sector universities (Hall \& Sobel, 2006). Similarly, since public sector institutions including universities heavily rely on government funding (Abbott \& Doucouliagos, 2003), this clearly highlights the importance and vitality of such funding prospects for their responsive performance. Moreover, government funding has a more particularized role when it comes to research and innovation and other similar prospects like entrepreneurial interventions (Muscio et al., 2013).

Notably, concerning to the moderation of government funding, recent study illustrated the effect of entrepreneurial orientation on performance and the response in terms of government funding policy as a moderator. The study underlined a significant moderating effect of government funding policy towards enriching performance (Soares et al., 2014). Though, government funding has been taken as a moderating variable in different contexts of study yet still; it has never been tested on the relationship of entrepreneurial training, entrepreneurial culture with organizational performance. Based on its significance and vitality, it was perceived that healthy government funding opportunities will enable public sector universities to further capitalize on entrepreneurial training initiatives to enhance organizational performance. Likewise, such funding prospects would also help infusing ingredients that are necessary to foster a positive entrepreneurial culture. Thus, the buffering potential of government funding on these relationships was highlighted to be an interesting theoretical arena to unleash for better understanding and prediction of organizational performance.

$\mathrm{H}_{3}$ : Government funding moderates the relationship between entrepreneurial training and organizational performance.

$\mathrm{H}_{4}$ : Government funding moderates the relationship between entrepreneurial culture and organizational performance

\section{Methodology}

\subsection{Sampling}

Three state level public sector universities were selected for the present study whereby, administrative authorities and faculty members with administrative positions were targeted for the present study. In particular, the sample included Head of Departments, Divisional Heads, Directors and Deputy directors, Dean and Deputy deans, Program coordinators, Senior Managers, Assistant Managers and section 
officers. These universities were selected based on their accelerated interest and focus on entrepreneurial understanding and development (Cedi, 2017).

Survey research method was deemed appropriate for the present research, keeping in view the large sample and scattered demographic locations of the targeted universities (Keeter, 2005). A total of 350 questionnaires were distributed through self-administered approach amongst the faculty members. Keeping in view the busy schedules and work nature of the respondents, the data was collected during the summer break period of 2017 (mid-June to mid-August) to ensure healthy response rate. The study managed to retrieve 268 questionnaires which resulted in an initial response rate of 76.6 percent. Notably, 19 questionnaires were discarded due to their incompleteness and hence, 249 questionnaire responses were taken further for final analysis and hypothesis testing. The study concluded with a final response rate of 71.1 percent which is significantly adequate as per the recommendations of Sekaran and Bougie (2016).

\subsection{Measures}

Prominent scales from the notable scholarly work were deployed in the resent study. To examine entrepreneurial culture, three-item scale by Yeung et al. (1991) was adapted. Accordingly, Rosli and Mahmood's (2013) two item scale was used to assess entrepreneurial training and four item scale to examine organizational performance by Covin and Slevin (1989). Lastly, the moderation of government funding was tested through ten-item scale by Lai (1997).

\subsection{Data Analysis and Interpretation}

Before the main analysis, the data was screened to ensure the assumptions regarding normality, linearity and multicollinearity (Tabachnick \& Fidell, 2007). Once these assumptions were confirmed, PLS path modeling approach was employed on the conceptual framework of the study (Wold, 1974; 1985) via Smart PLS 2.0 M3 software (Ringle et al., 2005). The PLS path modeling approach has been rigorously used as a multivariate analysis technique in the social sciences arena (Ahmed et al., 2017; Kura et al., 2015). The PLS path modeling approach encompasses two stage procedure which includes the assessment of measurement model and assessment of structural model (Hair et al., 2014; Henseler et al., 2009).

\subsection{Measurement Model Assessment}

This stage caters to the psychometric properties of the adapted measures which are examined including item reliability, internal consistency and discriminant validity (Hair et al., 2014; 2016). Therein, the individual item reliability is confirmed through assessing outer loadings of every measure of the construct (Hulland, 1999). Notably, the minimum cut-off, conventionally suggested by scholars is based on rule of thumb i.e. 0.50 (Chin, 1998). However, prominent scholars in the recent times have suggested a cut off of 0.70 as it makes the model more reliable (Carmines \& Zeller, 1979; Leal-Rodriguez et al., 2015; Hair et al., 2016). Following these suggestions, one item from government funding (GF4) was deleted (See Table 1). Next, the study assessed composite reliability coefficient to ascertain internal consistency reliability which is suggested to be equal or greater than 0.70 (Bagozzi \& Yi, 1988; Hair et al., 2016). Table 1 and Fig. 1 indicates that coefficient values of all the latent constructs ranged between 0.887 to 0.941 thus, confirming internal consistency reliability. Accordingly, the discriminant validity was also assessed following the propositions of Fornell and Larcker (1981). According to the authors the average variances scores should be examined at this stage which should be higher than 0.50 . Furthermore, the square root of AVE scores should be greater than the correlating values of the other constructs in the model. Table 2 in this regard shows that the AVE scores were above the suggested threshold of 0.50 whereby, Table 3 outlines that the square root scores of AVE were also greater than the correlating values of other constructs thus confirming significant discriminant validity. 


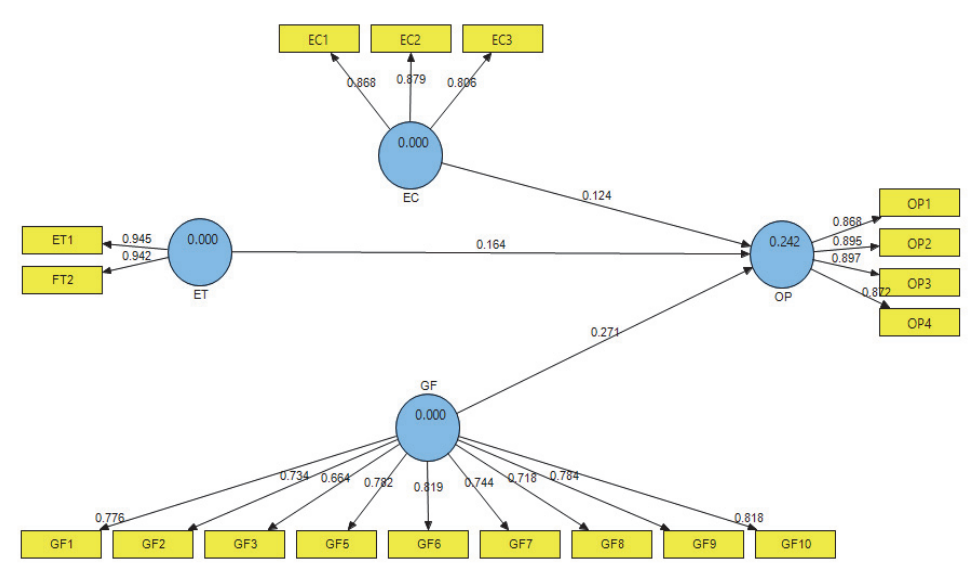

Fig.1. Measurement Model

ET= Entrepreneurial Training; EC= Entrepreneurial Culture; GF= Government Funding; OP= Organizational Performance .

Table 2

Factor Loadings and Reliability Scores

\begin{tabular}{cccc}
\hline Construct & Loadings & Composite Reliability & Average Variance Extracted \\
\hline Entrepreneurial Training & & 0.941 & 0.890 \\
\hline ET1 & 0.945 & & 0.725 \\
\hline FT2 & 0.941 & & \\
\hline Entrepreneurial Culture & & & \\
\hline EC1 & 0.868 & & 0.579 \\
EC2 & 0.878 & & \\
EC3 & 0.805 & & \\
\hline Government Funding & & & \\
\hline GF2 & 0.776 & & \\
GF3 & 0.734 & & \\
GF5 & 0.663 & & \\
GF6 & 0.781 & & 0.779 \\
GF7 & 0.819 & & \\
GF8 & 0.743 & & \\
GF9 & 0.717 & & \\
GF10 & 0.784 & & \\
\hline OP1 & 0.817 & & \\
\hline OP2 & & & \\
OP3 & 0.867 & & \\
OP4 & 0.894 & & \\
\hline
\end{tabular}

Table 3

Discriminant Validity

\begin{tabular}{ccccc}
\hline Construct & EC & ET & GF & OP \\
\hline EC & 0.8516 & & & \\
ET & 0.4283 & 0.9434 & 0.7612 & 0.8830 \\
GF & 0.6480 & 0.7347 & 0.4715 & 0.4159 \\
OP & 0.3697 & 0.5 & & \\
\hline
\end{tabular}

Note: Values in Bold are the square root of AVE of each latent construct.

\subsection{Structural Model Results}

The examination pertaining to the significance of path coefficients is performed in the structural model stage. The present study applied 5000 bootstraps procedures on 248 cases (Hair et al., 2014; 2016) to 
assess the direct causal relationships at the first place. Therein, hypothesis 1 asserted that entrepreneurial training would be positively associated with organizational performance. Results in Fig. 2 and Table 3 indicate that the respondents (faculty members) had strong positive views about entrepreneurial training provided to them and expressed its association with their enhanced organizational performance $(\beta=$ $0.3170 ; 4.92 ; \mathrm{p}<0.00)$. This hence leads towards accepting hypothesis 1 . Similarly, hypothesis 2 was formulated suggesting that healthy entrepreneurial culture would help employees boost their organizational performance. The present study has confirmed and thus, landed support to this hypothesis by resulting significant positive relationship between entrepreneurial culture and organizational performance $(\beta=0.2322 ; \mathrm{t}=3.524 ; \mathrm{p}<0.00)$. Henceforth, the study has confirmed the importance and vitality of entrepreneurial training and entrepreneurial culture to foster organizational performance. Fig. 2 and Table 3 may be referred for further reference in this regard.

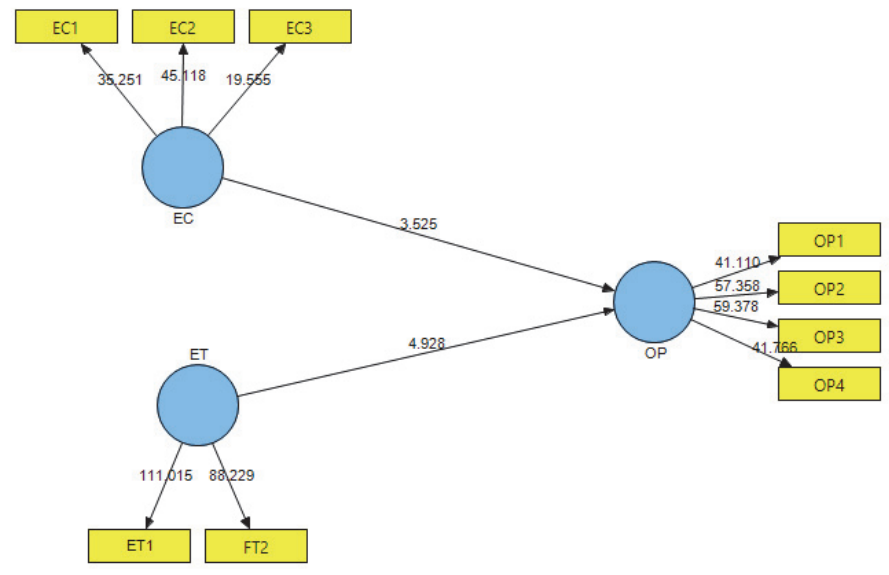

Fig. 2. Structural Modeling Result- Direct Effects

$\mathrm{ET}=$ Entrepreneurial Training; $\mathrm{EC}=$ Entrepreneurial Culture; $\mathrm{OP}=$ Organizational Performance.

\section{Effect Size and Predictive Relevance}

Effect size can be explained as the effect of predictor variable(s) on outcome variable(s) by the prospects of changes in the r-squared values (Chin, 1998). Principally, effect size is calculated through identifying the upsurge in the R-Square of the latent construct's to which the path is linked (Chin, 1998). The conventional formula for examining the effect size is as follows:

Effect size $f^{2}=\frac{R_{\text {included }}^{2}-R_{\text {iexcluded }}^{2}}{1-R_{\text {included }}^{2}}$

Cohin (1988) forwarded effect size (f2) scores whereby, exogenous variables with values equal or less than 0.02 can be considered as posing small effect and the ones with 0.15 and above as marking medium effects. Accordingly, variables with 0.35 or higher $\mathrm{f} 2$ values can be reported marking large effects. Based on this formula, the effect size of entrepreneurial training (0.062) and entrepreneurial culture $(0.065)$ resulted to be small upon organizational performance respectively. Accordingly, government funding also resulted posing small effect size on organizational performance. Parallel to this, the present study also applied Stone-Geisser test pertaining to the assessment of predictive relevance on the entire model through using blindfolding procedures (Geisser, 1974; Stone, 1974). For this, cross-validates redundancy measure $\left(Q^{2}\right)$ was employed for the examination of predictive relevance of the model (Hair et al., 2013; Stone, 1974). Principally, $Q^{2}$ is a criterion that asserts as to what length and context, the model envisages the data of omitted cases (Hair et al., 2014). Based on the explanations of Henseler et 
al. (2009), research framework with $Q^{2}$ statistic greater than zero-0 suggests having predictive relevance. The blindfolding procedures concluded $Q^{2}$ of 0.779 for the endogenous variable hence suggesting predictive relevance in the model (Chin, 1998).

\subsection{Moderation of Government Funding}

Upon the successful test of direct effects, the present study has tested the moderation of government funding on the relationship of entrepreneurial training and entrepreneurial culture with organizational performance. 5000 bootstraps were again applied on 248 cases to assess the significance of path coefficients of the moderator. In this, hypothesis 3 was posed that government funding would moderate the link between entrepreneurial training and organizational performance for individuals who have the availability of government funding than those who do not. Fig. 3 and Table 3 in this regard suggest that there was an insignificant interaction effect between entrepreneurial training and organizational performance $(\beta=-0.0681 ; t=0.850 ; p>0.1)$. Therefore, hypothesis was rejected. Accordingly, hypothesis 4 was formulated to assess the buffering effect of government funding on the relationship of entrepreneurial culture and organizational performance. The path modeling results have outlined significant interaction effect between entrepreneurial culture and organizational performance $(\beta=0.1437 ; \mathrm{t}=1.812$; $\mathrm{p}<0.05$ ) hence, landing support for hypothesis 4 . Fig. 3 and Table 4 provide further information in this regard.

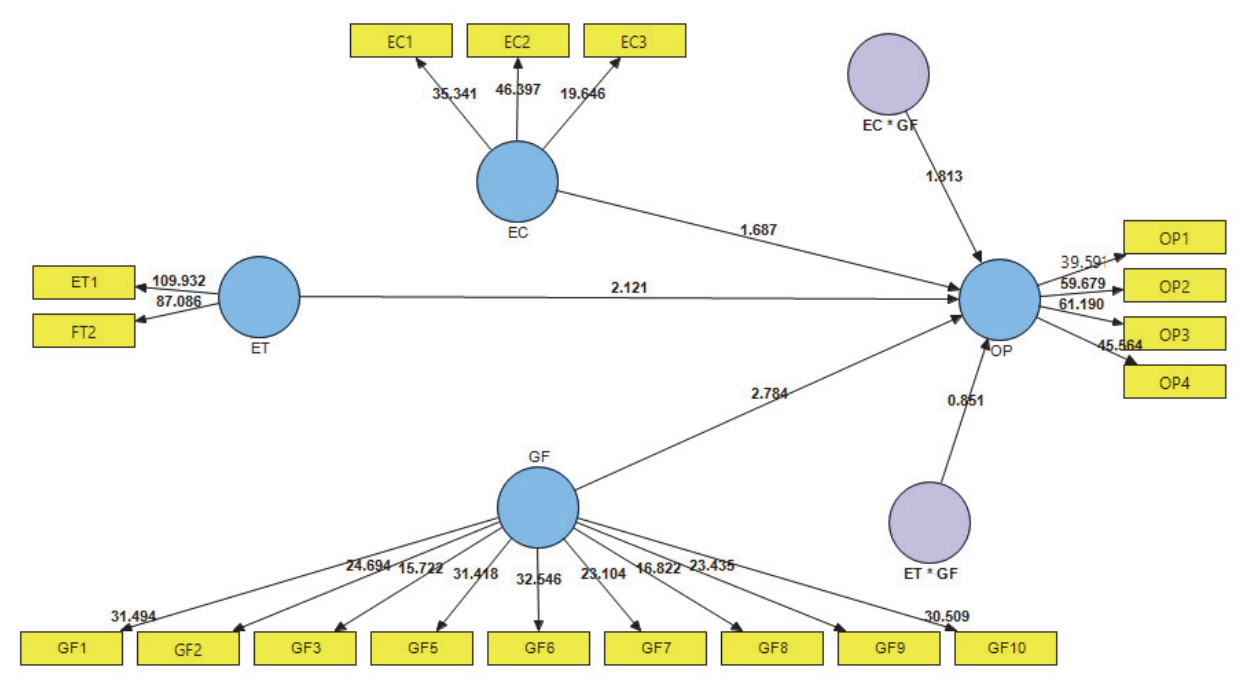

Fig. 3. Moderation Results

Table 4

Hypotheses Test Results

\begin{tabular}{lcccc}
\hline Relationship & $\beta$ & Std Deviation (STDEV) & T- Value & \\
\hline $\mathrm{ET} \rightarrow$ OP & 0.3170 & 0.314561 & 4.928 & Supported \\
$\mathrm{EC} \rightarrow$ OP & 0.2322 & 0.236405 & 3.524 & Supported \\
$\mathrm{ET} \times \mathrm{GF} \rightarrow$ OP & -0.0681 & -0.0759 & 0.080 & Not Supported \\
$\mathrm{EC} \times \mathrm{GF} \rightarrow$ OP & 0.1437 & 0.0793 & 1.812 & Supported \\
\hline
\end{tabular}

\section{Discussion}

The present study has attempted to examine how entrepreneurial training and entrepreneurial culture can influence organizational performance following the moderation of government funding. Results of the PLS path modeling indicated significant positive relationship between entrepreneurial training and 
organizational performance. Whilst addressing the research limitations (Rosli \& Mahmood, 2013), the present study has forwarded results consonance with previous study (Morris \& Jones, 1999), suggesting that entrepreneurial training can help employees gain skills that enable them to bring innovativeness, creativity and versatility in their work which hence results in enabling the business to boost its overall performance. In this, the study has outlined that employees working in top positions in the public-sector universities were provided with valuable entrepreneurial training prospects. Therein, such training prospects were helping them acquire necessary skills and knowledge to boost organizational performance. Hence, the findings outline a noteworthy role of entrepreneurial training interventions for public sector organizations to engage their top employees to make responsive decisions and work planning for enhanced organizational performance in a much more creative manner.

Accordingly, the study also found significant relationship between entrepreneurial culture and organizational performance. The findings have strengthened the empirical assertions of Aluku (2003) highlighting that encouraging entrepreneurial culture in an organization boosts enriches employees ' work prospects thus making them able to work with more uniqueness and effectivity towards assigned organizational activities. On a higher note, the study has addressed a major gap in the study on this relationship by giving a particularized attention on entrepreneurial culture. Entrepreneurial culture has a considerable role in boosting innovation, creativity and economic growth which principally is a result of enhanced performance of the enterprises in a country (Beugelsdijk, 2010). Organizations aspiring for augmenting their performance should engage top management for this since they have and can actually play a noteworthy role in creating, developing and maintaining entrepreneurial culture in a business setting (Lee \& Peterson, 2000). The findings of this study also support the reciprocity notion of the RBV theory. Due to which it could be inferred that employees working in structured departments and organizations will be able to galvanize impactful organizational performance (Barney, 1986; Wernerfelt, 1984).

Notably, the study found significant moderation of government funding on the relationship between entrepreneurial culture and organizational performance. The result educates that organizations with positive entrepreneurial culture can enrich its impact towards boosting performance through government funding. In order words, entities can amplify their entrepreneurial culture to enhance organizational performance through using investments provided by government for the purpose. The result has also landed support to the scholarly findings of Soares et al. (2014). Based on the findings, it can be understood that public sector universities can boost their entrepreneurial climate to further their organizational performance through using government funding. Such funding prospects would help infusing ingredients that are necessary to foster a positive entrepreneurial culture. Thus, the buffering potential of government funding on this relationship can be seen as an interesting research outcome for the enrichment of organizational performance. However, the study found no moderation of government funding on the entrepreneurial training and organizational performance relationship. Possible reasons can be the outlook of government funding received by the public sector universities in Pakistan. In parallel, this may also be due to lack of awareness of the institutional authorities pertaining on how they can potentially utilize government funding to provide learning and development opportunities for the organizational the employees for enhancing their entrepreneurial competencies. Government funding for training programs and university staffs' willingness to attend the training can promote the acquisition of a new skill which in turn helps to bring innovation into the system. In view of RBV theory as well newly acquired skillset will help organizations achieve competitive advantage and improve their performance (Wernerfelt, 1984).

\section{Implications of the Study}

This research has presented a research framework based on previous research theories for understanding the factors influencing the performance of public universities. The current study has contributed towards the body of knowledge concerning organizational performance. Although, very few empirical 
attempts have been made in prior studies to evaluate the performance of public sector organizations through the lens of entrepreneurship. Throughout the literature, performance has been viewed through the lens of human resource practices and policies, however, this study potentially contributes to address the performance of public universities via the lens of entrepreneurship. For instance, the factors that may influence the performance of the public universities such as public entrepreneurship, entrepreneurial training on innovation, entrepreneurial orientation and the moderating effects of government funding on the performance of public sector universities are highlighted. Previous entrepreneurship research in the public sector has mostly employed an untested "mix and match" methodology, focusing on individuals' traits and behaviors. However, the current research examined and explained the underlined phenomenon of public universities' performance in a broader sense with particularized focus on entrepreneurial training and culture. The outcomes of the present study showed significant support for the notion of the Incentive Theory of Motivation, Arousal Theory of Motivation and RBV. Since, RBV was previously applied across a variety of situations in the western context is now being applied to the entrepreneurial context and organizational performance in the Asian context in general, and Pakistani context in particular. Furthermore, one of the theoretical contributions of the present study is in the introduction of government funding as a moderator variable to better explain and understand the relationship between entrepreneurial training, entrepreneurial culture and organizational performance.

On the note of practical implications, it was observed that most of the public universities in Pakistan recognize the entrepreneurial opportunities and activities as a key source for them to enhance proficiency and deliver better service to stakeholders. Public universities of Pakistan should adopt a more organic type of entrepreneurship to encourage new ideas and take innovative opportunities as a source of growth. Accordingly, they will be able to adopt more nourished entrepreneurial strategies supporting the implementation of new ideas. From the perspective of entrepreneurial training for the top management of the universities, research results indicate that entrepreneurial training on innovation tends to enhance the performance of the public universities in Pakistan. Besides being tangible, there is a need for optimizing the use of entrepreneurial resources to compete in a dynamic environment, this is something which the public universities need to understand. Public universities should focus on innovative ways of generating sources of income to become sustainable even with reduced government funding. In this regard, public universities in Pakistan should take some effective actions to solve this issue of reduced funding from government rather than waiting for revised funding policy. The comprehensive framework of the study can possibly replace a variety of models of public sector management and corporate entrepreneurship applied in the public sector higher education institutions for effective public management.

\section{Limitations of the Study}

Despite the research yielding insightful findings and contributing to both theoretical and practical evidence, there are some limitations that need to be addressed. These limitations are predominantly in the respect of methodology and generalizability of the study. Such limitations have arisen largely due to time and money constraints. Similar to many academic studies, the current research study also presents the limitations and recommendations for future researchers to extend the current status of knowledge in the field of entrepreneurship. The current study strived to ensure unbiasness, it cannot be guaranteed particularly when it comes to how the target audience responds. This study is dependent on self-reported questionnaires data; hence the probability of common method variance may have prevailed because the variables were measured employing a single survey instrument. According to Avoid et al. (1991), the common method variance is more bothersome in analyzing the relationship between the attitudinal or psychological data obtained from respondents at one point in time. With respect to this study, both independent and dependent variables are based on perceptions data. Due to that reason, future research should include a method that could reduce common method variance, for instance of using perceptions data, the objective measures could be employed. The second limitation of the study research design used in this study was the survey questionnaire, employed with cross-sectional research 
strategy and gathered at a particular time period. Thirdly, this study investigated the impact of entrepreneurial training and entrepreneurial culture on organizational performance followed by the moderating role of government funding; some other variables could also be of value towards understanding these relationships.

\section{Scope for Further Research}

Interested researcher in this domain may consider the following. It might be useful to further investigate using samples from different national and international demographics to get a better idea about their viability and significance of the model. The first recommendation for future research is to address the different nature of organizational functions. The more detailed nature of public entrepreneurship can be determined with inter-functional coordination of engaged organizations. In the public sector universities, very few organizations can be estimated with having a different level of intensity towards entrepreneurial activities. Future research therefore may differentiate organizations based on their entrepreneurial activities and functions. This study was conducted with a cross sectional approach hence, future studies may consider conducting longitudinal study on the topic to address this limitation.

Secondly, this study was only focused on the public universities of Pakistan thus leaving the private universities unattended. Future studies may consider undertaking private universities also in order to establish further understanding and generalization of research results. Moreover, a detailed study may also be conducted by collecting data from private universities. The entrepreneurship model can be compared to establish similarities and differences between public and private universities in order to improve the public entrepreneurship model and come up with a more comprehensive model. Fifth, future studies may also incorporate other variables for potential moderating or mediating effect on the relationship between influencing factors and performance of public sector universities in Pakistan.

\section{Conclusion}

In a dynamic and highly competitive society, public sector universities in Pakistan have to uplift current competencies through utilizing their resources optimally in order to maximize the existing opportunities and cope up with identified challenges. The findings of the current study have concluded that public universities in Pakistan need to encourage entrepreneurial activities, identify the opportunities and avail those opportunities by adopting entrepreneurial practices. Public universities in Pakistan should seize such opportunities by coping with challenges on the way of building entrepreneurial capacity and promoting entrepreneurial action. There should be more emphasis on producing an entrepreneurial mindset among the public universities to engage in entrepreneurial ventures. The mindset can be developed with the help of entrepreneurial training related to innovation and building skills for better organizational performance whilst capitalizing upon government funding opportunities.

\section{Acknowledgement}

The authors would like to thank the anonymous referees for constructive comments on earlier version of this paper. 


\section{References}

Abbott, M., \& Doucouliagos, C. (2003). The efficiency of Australian universities: a data envelopment analysis. Economics of Education Review, 22(1), 89-97.

Ahmad, A. R., Farley, A., \& Soon, N. K. (2014). Categorisation of Public Universities Funding. Asian Social Science, 10(10), 57-67.

Ahmed, M. (2013). Higher Education Commission, Annual Report. Retrieved from: https://www.che.ac.za/sites/default/files/publications/CHE\%20Annual\%20Report $\% 202012$ 2013.pdf. [Accessed 27 July 2017]

Ahmed, U., A.H.A. Majid and L.M. Zin. (2016a). Construct validation of 17-item Utrecht University work engagement scale amongst the white collar employees of Malaysian Universities. International Journal of Academic Research in Business and Social Sciences, 6(5), 306-312.

Ahmed, U., Phulpoto, W., Umrani, W.A., Abbas, I.A. (2016b). Diving deep in employee training to understand employee engagement. The International Journal of Management, 5(1), 1-5.

Ahmed, U., Umrani, W. A., Pahi, M. H., \& Shah, S. M. M. (2017). Engaging PhD Students: Investigating the role of supervisor support and psychological capital in a mediated model. Iranian Journal of Management Studies, 10(2), 283-306.

Aluko, M. A. O. (2003). The impact of culture on organizational performance in selected textile firms in Nigeria. Nordic Journal of African Studies, 12(2), 164-179.

Antony, J. P., \& Bhattacharyya, S. (2010). Measuring organizational performance and organizational excellence of SMEs-Part 1: a conceptual framework. Measuring Business Excellence, 14(2), 3-11.

Ariff, M., \& Abubakar, S. Y. (2002). Strengthening entrepreneurship in Malaysia. Malaysian Economic Outlook: 1st Quarter 2002 Update, 1-22.

Bagozzi, R., \& Yi, Y. (1988). On the evaluation of structural equation models. Journal of the Academy of Marketing Science, 16(1), 74-94.

Beugelsdijk, S. (2010). Entrepreneurial culture, regional innovativeness and economic growth. In Entrepreneurship and culture (pp. 129-154). Springer, Berlin, Heidelberg.

Carmines, E. G., \& Zeller, R. A. (1979). Reliability and validity assessment (Vol. 17). London: Sage publications.

CEDI (2017). Co-operative and Entrepreneurship Development Institute. Retrieved from: http://cedi.uum.edu.my/[Acessed 25 May 2017].

Chin, W. W. (1998). The partial least squares approach to structural equation modeling. In G. A. Marcoulides (Ed.), Modern methods for business research (pp. 295-336). Mahwah, NJ: Lawrence Erlbaum.

Chung, T. D., Khosla, S., Badley, A. D., \& Jackson, M. R. (2014). Seeding Open Innovation Drug Discovery and Translational Collaborations to Leverage Government Funding: A Case Study of Strategic Partnership between Sanford-Burnham and Mayo Clinic. Collaborative Innovation in Drug Discovery, 451-486.

Codrina, C. L. (2008). A study of human resources management practices in Romanian private companies. Annals of the University of Oradea, Economic Science Series, 17(4), 179-183.

Covin, J. G., \& Slevin, D. P. (1989). Strategic management of small firms in hostile and benign environments. Strategic Management Journal, 10(1), 75-87.

Cumming, D. (2007). Government policy towards entrepreneurial finance: Innovation investment funds. Journal of Business Venturing, 22(2), 193-235.

Delaney, J. T., \& Huselid, M. A. (1996). The impact of human resource management practices on perceptions of organizational performance. Academy of Management Journal, 39(4), 949-969.

Else, H. (2016). Malaysia cuts public university funding. Retrieved from: http://www.themalaymailonline.com/malaysia/article/budget-2017-public-universities-suffer-almost-20pc-spendingcut\#yqt2kjyh127s5uQj.97 [Accessed 23 July 2017].

Fornell, C., \& Larcker, D. F. (1981). Evaluating structural equation models with unobservable variables and measurement error. Journal of Marketing Research, 18(1), 39-50.

Geisser, S. (1974). A predictive approach to the random effect model. Biometrika, 61(1), 101-107. 
Hair Jr, J. F., Hult, G. T. M., Ringle, C., \& Sarstedt, M. (2016). A primer on partial least squares structural equation modeling (PLS-SEM). Sage Publications.

Hair, J. F., Jr.; Hult, G. Tomas M.; Ringle, Christian M.; \& Sarstedt, Marko (2014). A primer on partial least squares structural equation modeling (PLS-SEM). Thousand Oaks, CA: Sage Publications.

Hair, Jr, F., Sarstedt, M., Hopkins, L., \& Kuppelwieser, V. G. (2014). Partial least squares structural equation modeling (PLS-SEM): An emerging tool in business research. European Business Review, 26(2), 106-121.

Hayton, J. C. (2005). Promoting corporate entrepreneurship through human resource management practices: A review of empirical research. Human Resource Management Review, 15(1), 21-41.

Henseler, J., Ringle, C. M., \& Sinkovics, R. R. (2009). The use of partial least squares path modeling in international marketing. In New challenges to international marketing (pp. 277-319). Emerald Group Publishing Limited.

Higher Education Commission Pakistan (2016). Public Sector universities/degree awarding institutions. Retrieved from: http:/www.hec.gov.pk/english/universities/Pages/DAIs/HEC-recognizedCampuses.aspx. [Accessed 9 April, 2016]

Hulland, J. (1999). Use of partial least squares (PLS) in strategic management research: A review of four recent studies. Strategic Management Journal, 20(2), 195-204.

Kearney, C., Hisrich, R. D., \& Roche, F. (2009). Public and private sector entrepreneurship: similarities, differences or a combination?. Journal of Small Business and Enterprise Development, 16(1), 26-46.

Keeter, S. ( 2005). Survey Research. In D. Druckman (Ed.), Doing research: Methods of Inquiry for conflict analysis (pp. 123-162). Thousand Oaks, CA: Sage Publications, Inc.

Kim, P. S., Pindur, W., \& Reynolds, K. (1995). Creating a new organizational culture: the key to total quality management in the public sector. International Journal of Public Administration, 18(4), 675709.

Kithae, P. P., Maganjo, R., \& Kavinda, L. (2013). Impact of entrepreneurship training on performance of micro and small enterprises (MSES) in Kenya: A case study of Embu Municipality. International Journal of Business and Management Review, 1(2), 1-17.

Kura, K. M., Shamsudin, F. M., \& Chauhan, A. (2015). Does self-regulatory efficacy matter? Effects of punishment certainty and punishment severity on organizational deviance. SAGE Open, 5(2), 114.

Kuvaas, B. (2008). A test of hypotheses derived from self-determination theory among public sector employees. Employee Relations, 31(1), 39-56.

Lai, Y. C. (1998). A study of the perceived effects of the changes in government funding policies for higher education by the chief fiscal officers in Taiwan's higher education institutions. Ph.D dissertation, Ohio University.

Leal-Rodríguez, A. L., Eldridge, S., Roldán, J. L., Leal-Millán, A. G., \& Ortega-Gutiérrez, J. (2015). Organizational unlearning, innovation outcomes, and performance: The moderating effect of firm size. Journal of Business Research, 68(4), 803-809.

Lee, S. M., \& Peterson, S. J. (2000). Culture, entrepreneurial orientation, and global competitiveness. Journal of World Business, 35(4), 401-416.

Lok, P. Westwood, R. \& Crawford, J. (2005). Perceptions of organisational subculture and their significance for organisational commitment. Applied Psychology: An International Review, 54(4), 490 514.

Lumpkin, G. T., \& Dess, G. G. (1996). Clarifying the entrepreneurial orientation construct and linking it to performance. Academy of Management Review, 21(1), 135-172.

Martins, E. C., \& Terblanche, F. (2003). Building organisational culture that stimulates creativity and innovation. European journal of Innovation Management, 6(1), 64-74.

McKenzie, D., \& Woodruff, C. (2013). What are we learning from business training and entrepreneurship evaluations around the developing world?. The World Bank Research Observer, 29(1), 48-82. 
Miron, E., Erez, M., \& Naveh, E. (2004). Do personal characteristics and cultural values that promote innovation, quality, and efficiency compete or complement each other?. Journal of Organizational Behavior, 25(2), 175-199.

MOF (2016). Ministry of Finance Budget 2017: Public universities suffer almost 20pc spending cut. Retrieved from: http:/www.themalaymailonline.com/malaysia/article/budget-2017-public-universities-suffer-almost-20pc-spending-cut\#6YGBSAY15OILWdCL.97. [Accessed 13 July, 2017]

Mok, K. H. (2005). Fostering entrepreneurship: Changing role of government and higher education governance in Hong Kong. Research Policy, 34(4), 537-554.

Morris, M. H., \& Jones, F. F. (1999). Entrepreneurship in established organizations: The case of the public sector. Entrepreneurship: Theory and Practice, 24(1), 71-71.

Muscio, A., Quaglione, D., \& Vallanti, G. (2013). Does government funding complement or substitute private research funding to universities?. Research Policy, 42(1), 63-75.

Noguera, M., Alvarez, C., \& Urbano, D. (2013). Socio-cultural factors and female entrepreneurship. International Entrepreneurship and Management Journal, 9(2), 183-197.

Nor, N. (2015). Entrepreneurship development policy in Malaysia. Retrieved from: http://ap.fftc.agnet.org/ap_db.php?id=439\&print=1 [Accessed 25 August, 2017].

Ringle, C. M., Wende, S., \& Will, S. (2005). SmartPLS 2.0 beta. University of Hamburg, Germany. Retrieved from https:// www.smartpls.com/\#downloads

Robuan, M. R. S., Jaén, I., \& Liñán, F. (2017). 5. Promoting entrepreneurship in an unfavourable setting: a case study of a university programme in Malaysia. The Emergence of Entrepreneurial Behaviour: Intention, Education and Orientation, 89-94.

Rosli, M. M. \& Mahmood, R. (2013). Moderating Effects of Human Resource Management Practices and Entrepreneur Training on Innovation and Small-Medium Firm Performance. Journal of Management and Strategy. 4(2), 60-69.

Sekaran, U., \& Bougie, R. (2016). Research methods for business: A skill building approach. New York: John Wiley \& Sons.

Soares, A. C., Moeljadi, Rohman, F. \& Solimun, (2014). Effect of Entrepreneurial orientation on business performance moderated by Government Policy (Study on SMEs in Timor Leste). International Journal of Business and Management Invention, 3(8), 64-71.

Stone, M. (1974). Cross-validatory choice and assessment of statistical predictions. Journal of the Royal Statistical Society. Series B (Methodological), 36(2), 111-147.

Tabachnick, B. G., \& Fidell, L. S. (2007). Using Multivariate Statistics (5th ed.). Boston, MA: Allyn \& Bacon/Pearson Education.

Úbeda-García, M., Marco-Lajara, B., Sabater-Sempere, V., \& Garcia-Lillo, F. (2013). Training policy and organisational performance in the Spanish hotel industry. The International Journal of Human Resource Management, 24(15), 2851-2875.

Umrani, W. A., Mahmood, R., \& Ahmed, U. (2016). Unveiling the direct effect of corporate entrepreneurship's dimensions on the business performance: A case of Big Five Banks in Pakistan. Studies in Business \& Economics, 11(1). 181-195.

Winter, M., Smith, C., Cooke-Davies, T., \& Cicmil, S. (2006). The importance of 'process' in rethinking project management: the story of a UK government-funded research network. International Journal of Project Management, 24(8), 650-662.

Wold, H. (1985). Partial Least Squares. In S. Kotz \& N. L. Johnson (Eds.), Encyclopedia of Statistical Sciences (Vol. 6, pp. 581-591). New York: Wiley.

Wold, H. (1974). Causal flows with latent variables: partings of the ways in the light of NIPALS modelling. European Economic Review, 5(1), 67-86.

Zare, A. H., \& Shakeri, F. (2011). The effect of organizational culture on corporate entrepreneurship in small and medium enterprises: A case study of small and medium enterprises in Yazd province. Organizational Culture Management, 9(23), 51-69.

Zhao, W., \& La Pira, F. (2013). Chinese Entrepreneurship: Institutions, Ecosystems and Growth Limits. Advances in Economics and Business, 1(2), 72-88. 


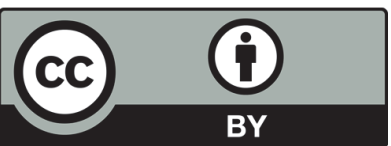

(C) 2019 by the authors; licensee Growing Science, Canada. This is an open access article distributed under the terms and conditions of the Creative Commons Attribution (CC-BY) license (http://creativecommons.org/licenses/by/4.0/). 